Western University

Scholarship@Western

Aboriginal Policy Research Consortium International (APRCi)

$1-4-2010$

\title{
Birthweight and natural deaths in a remote Australian Aboriginal community
}

Wendy E. Hoy

Jennifer L. Nicol

Follow this and additional works at: https://ir.lib.uwo.ca/aprci

Part of the Community Health and Preventive Medicine Commons, and the Other Public Health Commons

Citation of this paper:

Hoy, Wendy E. and Nicol, Jennifer L., "Birthweight and natural deaths in a remote Australian Aboriginal community" (2010).

Aboriginal Policy Research Consortium International (APRCi). 416.

https://ir.lib.uwo.ca/aprci/416 


\title{
Birthweight and natural deaths in a remote Australian Aboriginal community
}

\author{
Wendy E Hoy and Jennifer L Nicol
}

L ow birthweight is a risk factor for death in infants and young children, ${ }^{1}$ and probably predisposes adults to chronic disease and chronic disease mortality. ${ }^{2}$ Birthweights have been low in Aboriginal Australians since recording began, and higher death rates have been described in low birthweight Aboriginal infants and children. ${ }^{3-5}$ However, both infant and child mortality have been falling for some time,, 7 with more lower birthweight people surviving to adult life. Against this background, an epidemic of chronic disease has emerged among Aboriginal people. ${ }^{7,8}$

We have described associations of lower birthweight with higher blood pressures, hyperinsulinaemia, albuminuria and diabetes in young Aboriginal adults. ${ }^{9-11}$ Albuminuria predicts renal failure as well as ischaemic heart disease and cardiovascular and allcause natural death. ${ }^{12,13}$ This infers that lower birthweights contribute to deaths from chronic disease in Aboriginal adults, but such an association has not yet been described.

Historically, uncertainties about ethnic assignment and population denominators have thwarted accurate ascertainment of mortality rates in Indigenous people. ${ }^{7} \mathrm{We}$ describe trends in mortality and associations with birthweight in one Aboriginal group living in a remote location. In this study, community and ethnic assignment and the cohort denominator were both certain.

\section{METHODS}

The study community comprises a homogeneous ethnic group that lives on two islands off the coast of the Northern Territory, about $90 \mathrm{~km}$ from Darwin. In the 2006 census, the Aboriginal population was described as 2029 people, $43 \%$ of whom were aged less than 20 years. A mission ran the local health clinics over the described birth intervals. This community has very high rates of death and renal failure, as described previously. $^{12,14,15}$

Our study cohort consisted of people for whom birthweights were recorded, and who were born alive to Aboriginal mothers of this tribal group between 1956 and 1985. The study cohort was followed from birth through to 31 December 2006, with the

\section{ABSTRACT}

Objectives: To describe associations between birthweight and infant, child and early adult mortality from natural causes in a remote Australian Aboriginal community against a background of rapidly changing mortality due to better health services.

Design, participants and setting: Cohort study of 995 people with recorded birthweights who were born between 1956 and 1985 to an Aboriginal mother in a remote Australian Aboriginal community. Participants were followed through to the end of 2006.

Main outcome measures: Rates of natural deaths of infants (aged 0 to $<1$ year), children (aged 1 to $<15$ years) and adults (aged 15 to $<37$ years), compared by birth intervals (1956-1965, 1966-1975 and 1976-1985 for infants and children, and 1956-1962 and 1963-1969 for adults) and by birthweight.

Results: Birthweights were low, but increased over time. Deaths among infants and children decreased dramatically over time, but deaths among adults did not. Lower birthweights were associated with higher mortality. Adjusted for birth interval, hazard ratios for deaths among infants, children and adults born at weights below their group birthweight medians were $2.30(95 \% \mathrm{Cl}, 1.13-4.70)), 1.78(95 \% \mathrm{Cl}, 1.03-3.07)$ and 3.49

(95\% Cl, 1.50-8.09), respectively. The associations were significant individually for deaths associated with diarrhoea in infants, with cardiovascular and renal disease in adults, and marginally significant for deaths from pulmonary causes in children and adults.

Conclusion: The striking improvements in infant and child survival over time must be applauded. We confirmed a predisposing effect of lower birthweights on deaths in infants and children, and showed, for the first time, an association between lower birthweights and deaths in adults. Together, these factors are probably contributing to the current epidemic of chronic disease in Aboriginal people, an effect that will persist for decades. Similar phenomena are probably operating in developing countries.

MJA 2010; 192: 14-19

For editorial comment see page 5

primary outcome of interest being interim death from natural causes or continued survival.

Most babies were born in the bush before the observation period. Deliveries in the local clinic began in the mid 1950s, and were routine by the mid 1960s. High-risk deliveries were supervised at the Royal Darwin Hospital. Deliveries, the tribal or community assignment of the mother and the mother's name, were recorded in log books. Recording of birthweights for babies born in the local clinic was sporadic through the late 1950s, but was systematic by the mid 1960s, and was routine throughout for hospital deliveries. Birthweights were recorded in pounds and ounces initially, and later in kilograms and grams. Birth length, head circumference and placental weight were only recorded in the latter half of the birth intervals studied within our study period and gestational ages only in the last 4 years of the birth intervals (from 1981 on).

Terminal events were ascertained from the clinic death log, in which the death of every community member had been recorded, and from medical records and regional dialysis unit records. The vital status of individuals in the birth cohort who were not personally known to the investigators was confirmed by two Aboriginal community members of the study team, both of whom were born in the 1940s. They remembered the entire observation period, and knew everyone from the birth cohort who was still alive, and his or her whereabouts.

Causes of natural death were compiled from the death registers, in which the circumstances and clinical conditions surrounding death had been described in 


\section{Summary of birthweight data by birth interval for the entire study cohort of 995 people for whom birthweights were recorded}

\begin{tabular}{lcccc} 
Birth interval & $\begin{array}{c}\text { Total } \\
\text { births }\end{array}$ & $\begin{array}{c}\text { Range of } \\
\text { birthweights }\end{array}$ & $\begin{array}{c}\text { Mean } \\
\text { birthweight (SD) }\end{array}$ & $\begin{array}{c}\text { Birthweight } \\
<2.5 \mathrm{~kg}\end{array}$ \\
\hline $1956-1965$ & 308 & $1.13-4.31 \mathrm{~kg}$ & $2.65(0.49) \mathrm{kg}$ & $39.3 \%$ \\
$1966-1975$ & 332 & $1.00-4.35 \mathrm{~kg}$ & $2.70(0.54) \mathrm{kg}$ & $33.7 \%$ \\
$1976-1985$ & 355 & $1.07-4.60 \mathrm{~kg}$ & $2.87(0.52) \mathrm{kg}$ & $22.5 \%$ \\
Total & 995 & $1.00-4.60 \mathrm{~kg}$ & $2.74(0.53) \mathrm{kg}$ & $31.4 \%$ \\
\hline
\end{tabular}

\section{Categories of underlying or contributing causes of natural death}

\begin{tabular}{|c|c|c|}
\hline Age group and underlying or contributing cause & $\begin{array}{c}\text { Natural } \\
\text { deaths }\end{array}$ & $\begin{array}{c}\text { Causes } \\
\text { assigned* }\end{array}$ \\
\hline \multicolumn{3}{|l|}{ Infants (live birth, but death at $<1$ year) } \\
\hline Total & 35 & 54 \\
\hline Pulmonary (bronchitis, bronchiolitis, pneumonia) & & 16 \\
\hline Gastrointestinal (diarrhoea, gastroenteritis) & & 12 \\
\hline Sudden infant death or "cot death" & & 10 \\
\hline $\begin{array}{l}\text { Other (prematurity, birth injury, congenital abnormalities, meningitis, } \\
\text { encephalitis) }\end{array}$ & & 16 \\
\hline \multicolumn{3}{|l|}{ Children (death at 1 to $<15$ years) } \\
\hline Total & 55 & 72 \\
\hline Pulmonary (bronchitis, bronchiolitis, pneumonia, bronchiectasis) & & 26 \\
\hline Gastrointestinal (diarrhoea, gastroenteritis) & & 33 \\
\hline $\begin{array}{l}\text { Other (meningitis, encephalitis, viral infection, congenital abnormalities, } \\
\text { rheumatic heart disease, sudden infant death [two cases at age } 1 \text { to }<2 \\
\text { years]) }\end{array}$ & & 13 \\
\hline \multicolumn{3}{|l|}{ Adults (death at 15 to $<37$ years) } \\
\hline Total & 31 & 39 \\
\hline $\begin{array}{l}\text { Pulmonary (pneumonia, bronchitis, bronchiectasis, respiratory failure, } \\
\text { chronic obstructive pulmonary disease, primary pulmonary } \\
\text { hypertension, acute respiratory disease) }\end{array}$ & & 9 \\
\hline $\begin{array}{l}\text { Cardiovascular (heart attack, acute myocardial infarction, cardiac arrest, } \\
\text { congestive heart failure, pulmonary oedema, aortic valve disease, } \\
\text { atherosclerosis, coronary artery disease) }\end{array}$ & & 10 \\
\hline $\begin{array}{l}\text { Renal (maintenance dialysis commenced, death with terminal renal } \\
\text { failure without dialysis) }\end{array}$ & & 10 \\
\hline $\begin{array}{l}\text { Other (sepsis, liver failure, lupus, cirrhosis, pericarditis, colloid cyst, } \\
\text { congenital abnormalities, rheumatic heart disease) }\end{array}$ & & 10 \\
\hline
\end{tabular}

* Numbers of deaths by assigned causes exceed the total numbers of deaths because multiple conditions were often associated with deaths.

narrative. Deaths were often assigned multiple causes. Deaths were categorised by age. Infant deaths were defined as those occurring in the first year of life. We initially divided deaths among children into early childhood deaths (those occurring between ages 1 and $<5$ years), and later childhood deaths from age 5 to $<15$ years. However, as there were only four natural deaths among children aged 5 to $<15$ years, all childhood deaths were amalgamated to a single cate- gory as deaths occurring between ages 1 and $<15$ years. Deaths among adults were defined as those occurring at $\geqslant 15$ years of age, in accordance with World Health Organization criteria, ${ }^{16}$ and, in this study, before the age of 37 years.

Survival intervals for infants were calculated from birth until date of death at $<1$ year of age, or, for survivors, until the day they turned 1 year old. Survival intervals for children were calculated from age 1 year until death at $<15$ years, or, for survivors, until the day they turned 15 years old. Survival intervals for adults born before 1970 were calculated from age 15 until they died or started dialysis (equivalent to a natural renal death) at $<37$ years, or until they were censored from our study at age 37 years. Rates of death were calculated from the number of deaths divided by the personyears at risk over the relevant age-defined range. People who died from deaths of misadventure were censored on the date of death, contributing to the person-years of survival to that point, but their deaths were not included among natural deaths.

To evaluate infant and childhood deaths, the study cohort was divided into three "birth cohorts" according to the intervals in which they were born. These intervals were 1956-1965, 1966-1975 and 1976-1985. All participants were born more than 15 years before the analysis. Adult deaths (at 15 to <37 years) were compared for people born in 1956-1962 and 1963-1969, all of whom were born more than 37 years before the censor date. The associations of survival with intervals of birth and with categories of birthweight were calculated by Cox proportional hazards regression, and the associations of birthweight with survival were evaluated, with adjustment for interval of birth.

Finally, in each age category, mean birthweights of those who died a natural death were compared with those of survivors.

\section{Ethics approval}

Ethics approval for this work was granted separately for two projects: "The epidemiology and prevention of renal disease in Australian Aborigines", granted by the ethics committees of the Royal Darwin Hospital and Northern Territory Health Services; and "Chronic disease profiles and chronic disease deaths in a remote NT community", approved by the community's Health Board and Land Council, and the Human Research Ethics Committee of the Department of Health and Community Services, NT, the Menzies School of Health Research, NT and the University of Queensland, Brisbane, QLD. Members of the community were employed as staff in both projects.

\section{RESULTS}

Birthweights were recorded for 995 people born between 1956 and 1985. Box 1 shows birthweight data by birth interval for the entire study cohort. Average birthweights 


\section{Rates of natural death by birth interval and birthweight in infants (aged $<1$ year) and children (aged 1 to $<15$ years)}

\begin{tabular}{|c|c|c|c|c|c|c|}
\hline & $\begin{array}{l}\text { No. of infant } \\
\text { deaths/no. of } \\
\text { person-years }\end{array}$ & $\begin{array}{l}\text { Rate of deaths }(95 \% \mathrm{Cl}) \\
\text { per } 1000 \text { person-years }\end{array}$ & $P$ & $\begin{array}{l}\text { No. of childhood } \\
\text { deaths/no. of } \\
\text { person-years }\end{array}$ & $\begin{array}{l}\text { Rate of deaths }(95 \% \mathrm{Cl}) \\
\text { per } 1000 \text { person-years }\end{array}$ & $P$ \\
\hline \multicolumn{7}{|l|}{ Birth interval 1956-1965 } \\
\hline All natural deaths & $24 / 292.0$ & $82.2(55.1-122.6)^{\dagger}$ & & $44 / 3399$ & $12.9(9.6-17.4)$ & \\
\hline Birthweight* <2.66 kg & $15 / 140.7$ & $106.7(64.3-176.9)$ & & $27 / 1550$ & $17.4(11.9-25.4)$ & \\
\hline Birthweight* $\geqslant 2.66 \mathrm{~kg}$ & $9 / 151.3$ & $59.5(30.9-114.3)$ & 0.17 & $17 / 1849$ & $9.2(5.7-14.8)$ & 0.06 \\
\hline \multicolumn{7}{|l|}{ Birth interval 1966-1975 } \\
\hline All natural deaths & $8 / 325.5$ & $24.6(12.3-49.1)^{\dagger}$ & & $10 / 4310$ & $2.3(1.2-4.3)$ & \\
\hline Birthweight* <2.68 kg & $7 / 157.9$ & $44.3(21.1-93.0)$ & & $5 / 2061$ & $2.4(1.0-5.8)$ & \\
\hline Birthweight* $\geqslant 2.68 \mathrm{~kg}$ & $1 / 167.6$ & $6.0(0.8-42.0)$ & 0.03 & $5 / 2249$ & $2.2(1.0-5.3)$ & 0.91 \\
\hline \multicolumn{7}{|l|}{ Birth interval 1976-1985 } \\
\hline All natural deaths & $3 / 353.6$ & $8.5(2.7-26.3)^{\dagger}$ & & $1 / 4903$ & $0.2(0-1.4)$ & \\
\hline Birthweight* <2.86 kg & $2 / 176.8$ & $11.3(2.8-45.2)$ & & $1 / 2450$ & $0.4(0.1-2.9)$ & \\
\hline Birthweight* $\geqslant 2.86 \mathrm{~kg}$ & $1 / 176.8$ & $5.7(0.8-40.2)$ & 0.56 & $0 / 2453$ & 0 & 0.32 \\
\hline
\end{tabular}

were low, and rates of low birthweight were high, but average birthweights increased and low birthweight rates decreased over the period of observation.

Deaths among people included in the survival analysis included 121 natural deaths and 24 deaths of misadventure (caused by accidents, burns, drowning, jellyfish stings, crocodile attacks, homicides, suicides and intoxication). There were four deaths of misadventure among infants, eight among children and 12 among adults.

Box 2 shows the numbers and assigned causes of natural deaths in each age group. Among the 121 natural deaths, there were 165 assigned causes. Prominent causes of death were gastrointestinal and pulmonary causes in infants, and gastrointestinal and pulmonary causes in children. Among adults (347 people born before 1970), 31 (8.9\%) died of natural causes before their 37 th birthday. Their ages at death ranged from 16.0 to 36.9 years (median, 30.9 years). Pulmonary, cardiovascular, renal and other causes of death were all prominent, and none had diabetes recorded among causes of death.

Box 3 shows that there were marked reductions in infant death rates over the three successive 10-year birth intervals (trend significant). Twenty-four of the 35 infant deaths occurred in the first birth interval, eight in the second, and three in the third. The infant death rate in the most recent birth interval was about one-tenth of that in the first birth interval. There was also a trend towards higher death rates among infants born at a weight below each cohort's median birthweight. This phenomenon is shown graphically in Box 4, A.

Box 3 also shows dramatic reductions over time in deaths among children; 44 of the 55 natural deaths among children occurred in the first birth interval, 10 in the second and one in the third birth interval. Rates of death among children born in the third birth interval were only $1.5 \%$ of those in children born in the first interval. Box 3 also shows a trend towards higher death rates in children who were born at weights below their group median birthweights (this is also illustrated in Box 4, B).

As shown in Box 5, death rates in young adults born in the more recent birth interval were $77 \%$ of those born in the earlier interval, a difference that was not significant. However, in both birth cohorts, death rates

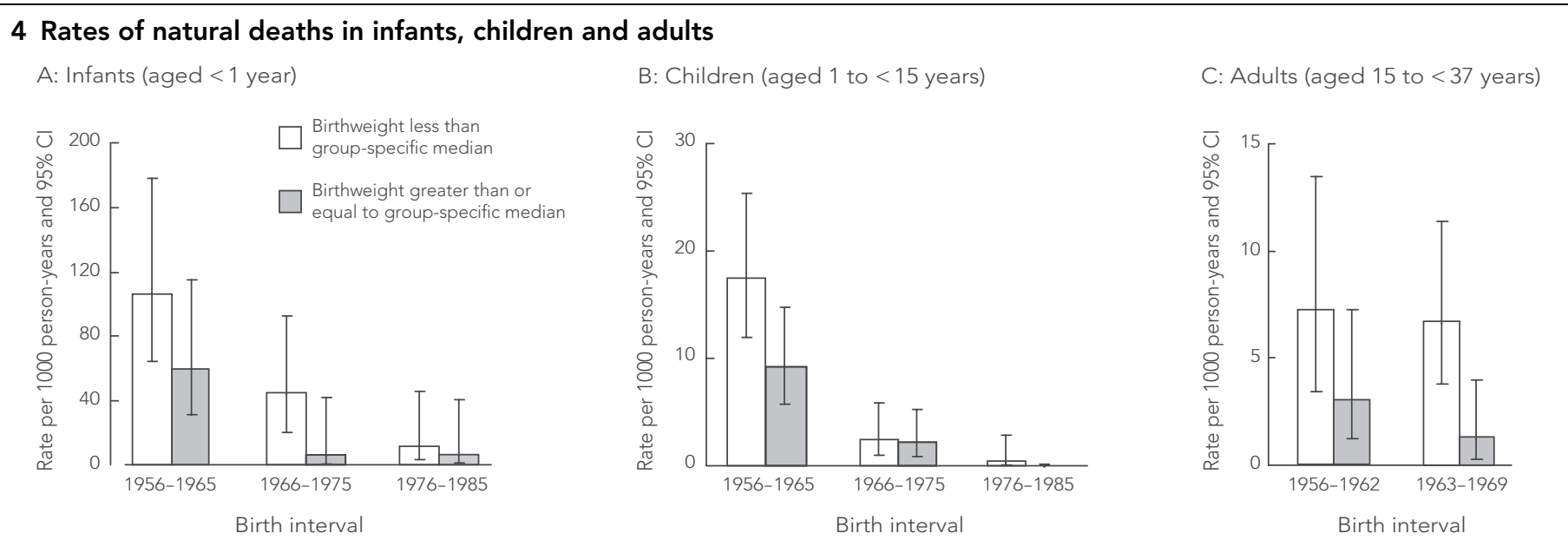




\begin{tabular}{|c|c|c|c|}
\hline \multicolumn{4}{|c|}{$\begin{array}{l}5 \text { Rates of natural death in adults (aged } 15 \text { to }<37 \text { years) by birth interval and } \\
\text { birthweight }\end{array}$} \\
\hline & $\begin{array}{l}\text { No. of deaths/no. } \\
\text { of person years }\end{array}$ & $\begin{array}{l}\text { Rate of deaths }(95 \% \mathrm{Cl}) \\
\text { per } 1000 \text { person-years }\end{array}$ & $P$ \\
\hline \multicolumn{4}{|l|}{ Birth interval 1956-1962 } \\
\hline All natural deaths & $15 / 3060$ & $4.9(3.0-8.1)$ & \\
\hline Birthweight* <2.61 kg & $10 / 1386$ & $7.2(3.9-13.4)$ & \\
\hline Birthweight* $\geqslant 2.61 \mathrm{~kg}$ & $5 / 1675$ & $3.0(1.2-7.2)$ & 0.10 \\
\hline \multicolumn{4}{|l|}{ Birth interval 1963-1969 } \\
\hline All natural deaths & $16 / 4238$ & $3.8(2.3-6.2)$ & \\
\hline Birthweight* $<2.72 \mathrm{~kg}$ & $13 / 1942$ & $6.7(3.9-11.5)$ & \\
\hline Birthweight* $\geqslant 2.72 \mathrm{~kg}$ & $3 / 2296$ & $1.3(0.4-4.1)$ & 0.004 \\
\hline
\end{tabular}

were higher among those below their group median birthweights (Box 4, C), and this difference was significant for those born in the second birth interval.

Box 6 shows that mean birthweights of those who died a natural death were consistently lower than those who were survivors. These differences were significant for deaths in all three age categories, with an average of $300 \mathrm{~g}$ difference for infants $(2.45 \mathrm{~kg}$ [SD, $0.63 \mathrm{~kg}] \mathrm{v} 2.75 \mathrm{~kg}$ [SD, $0.52 \mathrm{~kg}$ ]; $\quad P<0.001), 250 \mathrm{~g}$ for children $(2.51 \mathrm{~kg}[\mathrm{SD}, 0.50 \mathrm{~kg}] \mathrm{v} 2.77 \mathrm{~kg} \quad[\mathrm{SD}$, $0.52 \mathrm{~kg}$ ]; $P<0.001$ ) and almost $250 \mathrm{~g}$ for young adults $(2.43 \mathrm{~kg}$ [SD, $0.39 \mathrm{~kg}] \mathrm{V}$ $2.67 \mathrm{~kg}$ [SD, $0.51 \mathrm{~kg}$ ]; $P=0.002)$.

Box 7 shows that, for those with birthweights below their group median, the risks of natural deaths among infants, children, and adults were increased 2.30, 1.78 and 3.49 times relative to those of higher birthweights, adjusted for sex and for birth interval. The differences were still significant for those born below $2.5 \mathrm{~kg}$. Those associations existed for both females and males.

This association of lower birthweights with higher death rates was consistent for most causal categories of natural death. The relationships were significant around the birthweight median for infant deaths with a gastrointestinal cause (Box 8, A). They were marginally significant around the birthweight median for pulmonary deaths in children (Box 8, B), and, for birthweights below $2.5 \mathrm{~kg}$, were significant for pulmonary deaths and marginally significant for gastrointestinal deaths $(P=0.07)$. They were significant for pulmonary deaths in young adults, marginally significant for cardiovascular and renal deaths separately, and significant for cardiovascular and renal deaths combined (Box 8, C).
Among the 12 young adults who died by misadventure, 11 were men. Nine of these were born in the first birth interval and three were born in the second. Three deaths were suicides (all by men). All 12 deaths by misadventure occurred in people born at weights above their group median.

\section{DISCUSSION}

The accuracy of the data in our study was optimised by having a defined denominator for those at risk (those with documented birthweight), assured ethnic assignment through identification of the mother, ascertainment of outcome from clinical records, and by confirmation of vital status through senior community members.

The reductions in infant and child deaths over time were dramatic. Of those born in the first, second and third of our delineated birth intervals, $22.1 \%, 5.4 \%$ and $1.1 \%$, respectively, died before their 15 th birthday. Improvement occurred across the birthweight spectrum, although the greatest reduction in numbers of deaths was among those born at lower birthweights.

\section{Comparison of birthweight among those who died natural deaths and survivors, by age category}

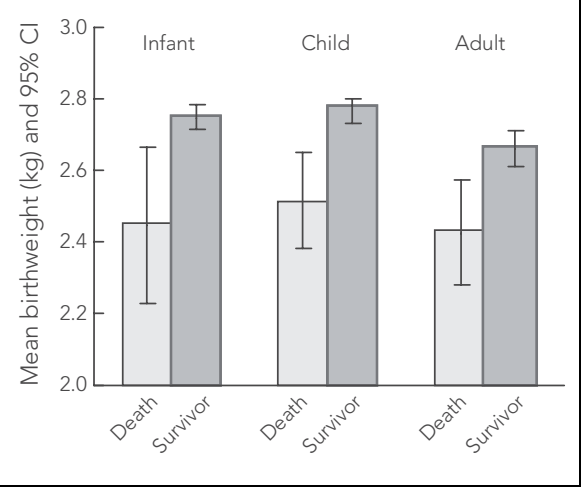

Many factors have probably contributed to this improvement. The care delivered by the mission clinics has had a major impact. In addition, this community, only a short plane flight from Darwin, was an early beneficiary of systematic protocols of hospital resuscitation of sick infants, and of strengthened local programs of maternal, infant and child care, instituted by the NT's first paediatrician, Alan Walker, who arrived in Darwin in 1964. Changes of a similar magnitude subsequently occurred in other communities. ${ }^{6,7}$

Discernment of trends in natural deaths in young adults was limited by small numbers of deaths thus far. The similar proportions of young adult deaths in the first and second adult birth interval (10.1\% v 8.0\%) are compatible with the minimal change in mortality of young Aboriginal adults (aged 2544 years) between 1981 and 1999 reported by NT Health Services. ${ }^{17}$ It is also compatible with a review of life expectancy from 1966 to 2001, which showed reduced mortality among Indigenous adults overall, but no decrease in mortality from chronic disease. ${ }^{18}$ However, the rate of increase of

\section{Hazard ratios for all-cause natural death by birthweight below the median for each age group, and below $2.5 \mathrm{~kg}$, adjusted for birth interval, age and sex}

\begin{tabular}{|c|c|c|c|c|c|}
\hline \multirow[b]{2}{*}{ Age group } & \multirow[b]{2}{*}{$\begin{array}{l}\text { No. of } \\
\text { deaths }\end{array}$} & \multicolumn{2}{|c|}{$\begin{array}{l}\text { Birthweight below } \\
\text { group median* }\end{array}$} & \multicolumn{2}{|c|}{ Birthweight $<2.5 \mathrm{~kg}$} \\
\hline & & $\begin{array}{c}\text { Hazard ratio } \\
(95 \% \mathrm{Cl})\end{array}$ & $P$ & $\begin{array}{c}\text { Hazard ratio } \\
(95 \% \mathrm{Cl})\end{array}$ & $P$ \\
\hline Infants (aged < 1 year) & 35 & $2.30(1.13-4.70)$ & 0.02 & $2.35(1.20-4.61)$ & 0.01 \\
\hline Children (aged 1 to $<15$ years) & 55 & $1.78(1.03-3.07)$ & 0.04 & $1.88(1.11-3.20)$ & 0.02 \\
\hline Adults (aged 15 to $<37$ years) & 31 & $3.49(1.50-8.09)$ & 0.004 & $2.69(1.32-5.51)$ & 0.007 \\
\hline
\end{tabular}




\section{Hazard ratios for natural deaths in infants, children and adults for birthweight less than the group median relative to birthweight higher than the group median by underlying or associated cause of death, adjusted for birth interval, age and sex}

A: Infants (aged $<1$ year)

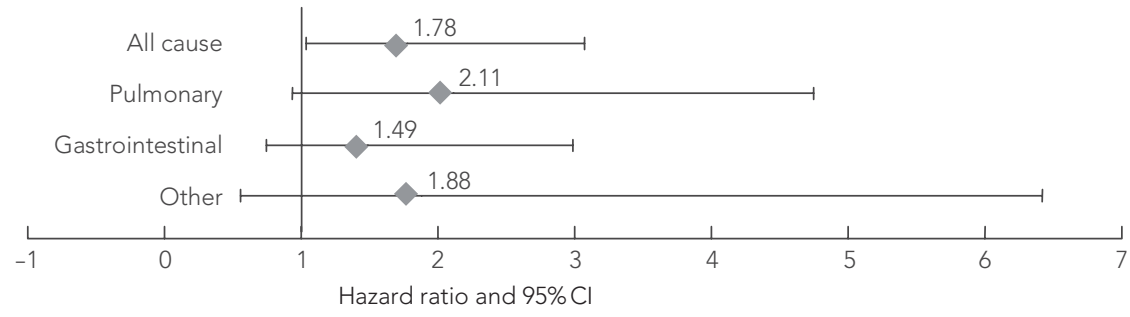

B: Children (aged 1 to $<15$ years)

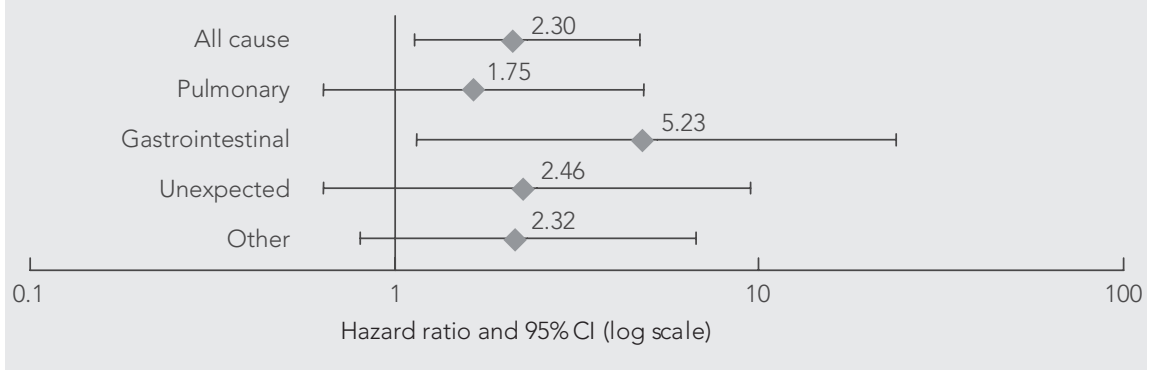

C: Adults (aged 15 to $<37$ years)

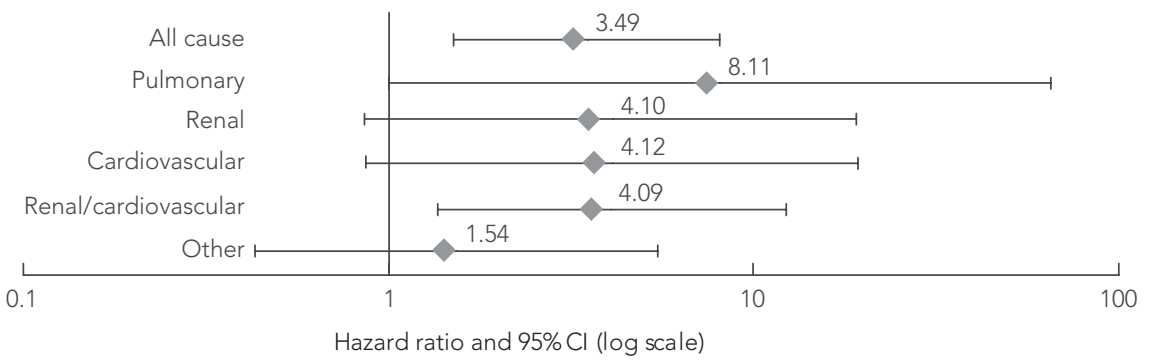

deaths from chronic disease might be slowing, and the causes of death assigned within that category are apparently changing. ${ }^{14,18-20}$

Our study confirms that birthweights have been low in remote Aboriginal settings as far back as records go, although they are improving. The contributions of preterm birth and intrauterine growth restriction (IUGR) cannot be ascertained, and have probably varied over time. In a retrospective study of 819 Aboriginal newborn babies at Royal Darwin Hospital from 1969 to 1983 , $23.2 \%$ weighed less than $2.5 \mathrm{~kg}$ at birth, and the predominant cause of this low birthweight was considered to be IUGR. ${ }^{21}$ A later prospective study from 1987 to 1991 of 570 Aboriginal infants born at the same hospital found that $13 \%$ weighed less than $2.5 \mathrm{~kg}$ at birth, $7 \%$ were premature, and fully $22.7 \%$ (of 502) were small for gestational age
$(<10$ th percentile), which represents IUGR. ${ }^{22}$ However, a Western Australian study from 1979 to 1983, and a study of 810 Aboriginal babies born at the Cairns Hospital (serving Far North Queensland) from 1992 to 1994 concluded that the major contributor to low birthweight was preterm birth. ${ }^{23,24}$

Lower birthweights predisposed to higher mortality in infants, children and adults. In infants, the strong predisposing effects of lower birthweight on deaths assigned a gastrointestinal cause is compatible with the high prevalence of diarrhoea in infants with failure to thrive. However, other causes of death, including sudden infant death, tended towards an association with low birthweight. In children and adults, the effect was strongest for deaths from pulmonary causes. However, for deaths at all ages, wherever a trend existed, it was in the direction of a predisposing effect of lower birthweights on that causal category of death, except for "other" deaths in young adults.

The association of low birthweight with infant and childhood deaths is well recognised. However, our study is the first to demonstrate a predisposing effect on adult deaths in any Australian group. The effect operates around median values of birthweight, as well as the standard "low birthweight" cutoff, and for all-cause natural death in every age group. The striking associations with pulmonary deaths in children and adults is consistent with the adverse effects of IUGR, prematurity and maternal smoking on fetal lung development, and reports of impaired lung function and accelerated lung ageing in people born at low birthweights. ${ }^{2,25}$ The significant association of lower birthweights with the combined outcome of young adult deaths with renal and cardiovascular causes, which are powerfully linked, $8,9,12,13,20$ is also noteworthy. Association of birthweight with natural deaths in adults might become more prominent as the birth cohorts move into the age groups where chronic diseases are more fully expressed. ${ }^{8}$

With lower mortalities in infancy and childhood, many more individuals born at lower birthweights are surviving to adult life. According to the Barker hypothesis and much supporting data, including in this specific tribal group, ${ }^{9-11}$ these adults are at higher risk of chronic diseases. Thus the epidemic of chronic disease in Aboriginal people appears to be a legacy, in part, of earlier therapeutic triumphs. In multideterminant models of disease, birthweight is only one of several potential risk factors, but its effect might partly account for the incomplete explanation of cardiovascular and renal risk in multivariate models which consider only more traditional risk factors., ${ }^{9,26}$

The reductions in mortality over time must be applauded. They refute pessimistic views of trends in adult Aboriginal mortality, and predict further improvements as more robust birthweights are sustained, if other risk factors do not increase. Birthweights in this community (mean, about $3100 \mathrm{~g}$ ) and in Aboriginal people nationwide (mean, $3157 \mathrm{~g}$ ) remain low relative to the nationwide average of $3369 \mathrm{~g}$, and Aboriginal people have more than twice the rate of low birthweight. ${ }^{7}$ It is not clear what an ideal birthweight should be in the Aboriginal population, but intrauterine development is 
still frequently impaired by low maternal body mass index, low maternal age, and high rates of smoking and alcohol use. ${ }^{27}$

Similar phenomena are probably operating in other populations and "developing" countries experiencing reductions in infant mortality and burgeoning chronic disease rates. Historical perspectives allow more sophisticated interpretation of such events and trends.

\section{ACKNOWLEDGEMENTS}

We thank the study community and their Land Council for their continued great interest and collaboration in the ongoing studies, now in their 21st year. John Mathews, then Director of the Menzies School of Health Research, encouraged exploration of the Barker hypothesis among the Aboriginal populations of the Northern Territory. Sister Maureen Carey and Alan Walker allowed and facilitated access to delivery and birthweight records, and Emma Kile documented and first analysed those birth records, in pursuit of her BMedSci. We thank the staff of the community's clinics for access to clinical charts and death records, and Suresh Sharma, Hilary Bloomfield, Bernard Tipiloura, Hadley Tungutalum and other community liaison workers for constantly updating death records. Staff of the Menzies School of Health Research have contributed much administrative, laboratory, statistical and technical assistance over the years. Wendy Hoy was based at the Menzies School of Health Research during some of this work, and has a continuing honorary appointment there. Susan Mott has provided excellent administrative, technical and analytical help. Funding was provided by: National Health and Medical Research Council project grants (numbers 921134, 951342 and 320860), and The Colonial Foundation of Australia. Janssen Cilag of Australia, Amgen, Servier, Kidney Health Australia and Rio Tinto have also contributed support. The role of all funding bodies was solely the provision of funding.

\section{COMPETING INTERESTS}

None identified.

\section{AUTHOR DETAILS}

Wendy E Hoy, FRACP, Professor of Medicine, and Director

Jennifer L Nicol, BSc(Hons), MSc(Stats),

Research Assistant

Centre for Chronic Disease, School of

Medicine, University of Queensland, Brisbane,

QLD.

Correspondence: w.hoy@uq.edu.au

\section{REFERENCES}

1 McCormick M. The contribution of low birth weight to infant mortality and childhood morbidity. N Engl J Med 1985; 312: 82-90.

2 Barker DJP. Mothers, babies and disease in later life. London: BMJ Publishing Group, 1994.

3 Read JS, Clements JD, Klebanoff MA. Moderate low birthweight and infectious disease mor- tality through infancy and childhood. Am J Epidemiol 1994; 140: 721-733.

4 Alessandri LM, Chambers HM, Garfield C, et al. Cumulative mortality in children aged 1 to 6 years born in Western Australia from 1980-89. Arch Dis Child 1999; 80: 15-20.

5 Freemantle CJ, Read AW, de Klerk NH, et al. Patterns, trends and increasing disparities in mortality for Aboriginal and non-Aboriginal infants born in Western Australia 1980-2001. Lancet 2006; 367: 1758-1766.

6 Northern Territory Department of Health. Maternal and infant mortality in the Northern Territory, 1974-1979. Issue no. 26. Darwin: Northern Territory Department of Health, 1980.

7 Australian Institute of Health and Welfare. Australia's Health 2008. Australia's health no. 11. Canberra: AlHW, 2008. (AlHW Cat No. Aus 99.) http://www.aihw.gov.au/publications/ index.cfm/title/10585 (accessed Nov 2009).

8 Hoy WE, Kondalsamy Chennakesavan S, Katz I. A chronic disease outreach program for Australian Aboriginal communities. Kidney Int 2005; 98: S76-S82.

9 Hoy WE, Kondalsamy-Chennakesavan S, Smith J, et al. The Aboriginal Chronic Disease Outreach Program. Submitted to Kidney Health Australia by the Centre for Chronic Disease, The University of Queensland, and Kidney Disease Research and Prevention. October 31 2004. http://www.healthinfonet.ecu.edu.au/ health-resources/bibliography?lid=3289\&ref $=5$ (accessed Nov 2009).

10 Singh GR, Hoy WE. The association between birthweight and current blood pressure: a cross-sectional study in an Australian Aboriginal community. Med J Aust 2003; 179: 532-535.

11 Hoy WE, Kile E, Rees M, Mathews JD. Low birthweight and renal disease in Australian Aborigines. Lancet 1998; 352: 1826-1827.

12 Hoy WE, Wang Z, Baker PRA, et al. The natural history of renal disease in Australian Aborigines. Part 2. Albuminuria predicts natural death and renal failure. Kidney Int 2001; 60: 249-256.

13 Wang Z, Hoy WE. Albuminuria and incident coronary heart disease in Australian Aboriginal people. Kidney Int 2005; 68: 1289-1293.

14 Australian Bureau of Statistics. Trends in mortality by causes of death in Australia, the states and territories during 1971-92 and in the regions during 1991-92, 1971-92. Canberra: ABS, 1995. (Cat. No. 3130.0.) http:// www.abs.gov.au/AUSSTATS/abs@.nsf/Prod
uctsbyTopic/DBB5A2050F91EF3ACA25722E00 1A3A2E?OpenDocument (accessed Nov 2009).

15 Spencer JS, Silva DT, Snelling P, Hoy WE. An epidemic of renal failure among Australian Aborigines. Med J Aust 1998; 168: 537-541.

16 World Health Organization. World health statistics 2009. Geneva: WHO, 2009.

17 Li Shu Q, Guthridge SL. Mortality in the Northern Territory, 1981-2000. Darwin: NT Department of Health and Community Services, 2004

18 Thomas DP, Condon JR, Anderson IP, et al. Long-term trends in Indigenous deaths from chronic diseases in the Northern Territory: a foot on the brake, a foot on the accelerator. Med J Aust 2008; 185: 145-149.

19 Condon JR, Barnes T, Cunningham J, Smith L. Improvements in Indigenous mortality in the Northern Territory over four decades. Aust N Z J Public Health 2004; 28: 445-451.

20 Hoy WE, Mathews JD, McCredie DA, et al. The multidimensional nature of renal disease: rates and associations of albuminuria in an Australian Aboriginal community. Kidney Int 1998; 54: 1296-1304.

21 Gogna NK, Smiley M, Walker AC, Fullerton P. Low birthweight and mortality in Australian Aboriginal babies at the Royal Darwin Hospital: a 15 year study. Aust Paediatr J 1986; 22: 281-284.

22 Sayers SM, Powers JR. Birth size of Australian Aboriginal babies. Med J Aust 1993; 159: 586591.

23 Stanley FJ, Mauger S. Birth-weight patterns in Aboriginal and non-Aboriginal singleton adolescent births in Western Australia, 1979-83. Aust N Z J Obstet Gynaecol 1986; 26: 49-54.

24 Humphrey MD. Low Aboriginal birth weight, prematurity versus intrauterine growth restriction. Aust N Z J Obstet Gynaecol 1996; 36: 126-128.

25 Chan KN, Noble-Jamieson CM, Elliman A, et al. Lung function in children of low birthweight. Arch Dis Child 1989; 64: 1284-1293.

26 Wang Z, Hoy WE. Is the Framingham coronary heart disease absolute risk function applicable to Aboriginal people? Med J Aust 2005; 182: 66-69.

27 Sayers SM, Powers J. Risk factors for Aboriginal low birthweight and intrauterine growth retardation and preterm birth in the Royal Darwin Hospital region. Aust N Z J Public Health 1997; 21: 524-530.

(Received 11 Feb 2009, accepted 18 Aug 2009) 